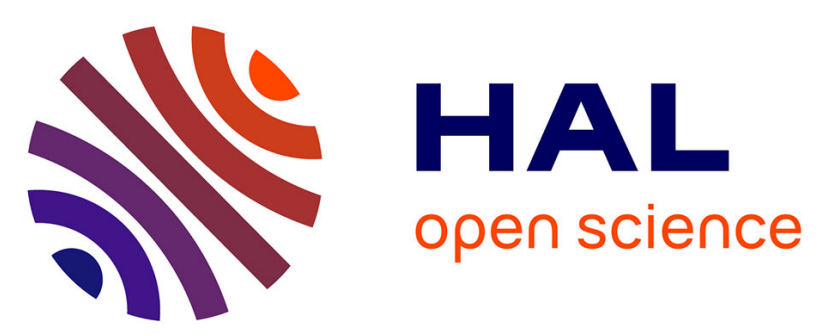

\title{
Rebirth-20 - Relive After the COVID-19 and Keep Preventing Against it
}

Eloïse Minder, Maël Sombret, Jean-Rémy Chardonnet, Frédéric Merienne

\section{To cite this version:}

Eloïse Minder, Maël Sombret, Jean-Rémy Chardonnet, Frédéric Merienne. Rebirth-20 - Relive After the COVID-19 and Keep Preventing Against it. 2021 IEEE Conference on Virtual Reality and 3D User Interfaces, Mar 2021, Lisbonne, Portugal. pp.673-674, 10.1109/VRW52623.2021.00219 . hal03192586

\section{HAL Id: hal-03192586 https://hal.science/hal-03192586}

Submitted on 8 Apr 2021

HAL is a multi-disciplinary open access archive for the deposit and dissemination of scientific research documents, whether they are published or not. The documents may come from teaching and research institutions in France or abroad, or from public or private research centers.
L'archive ouverte pluridisciplinaire HAL, est destinée au dépôt et à la diffusion de documents scientifiques de niveau recherche, publiés ou non, émanant des établissements d'enseignement et de recherche français ou étrangers, des laboratoires publics ou privés. 


\title{
Rebirth-20 - Relive After the COVID-19 and Keep Preventing Against it
}

\author{
E. Minder* \\ M. Sombret ${ }^{\dagger}$ \\ J.-R. Chardonnet \\ F. Merienne $e^{\S}$ \\ Arts et Metiers Institute of Technology, LISPEN, HESAM Université, 2 Rue Thomas Dumorey, 71100 Chalon-sur-Saône, France
}

\begin{abstract}
For the 2021 IEEE VR 3DUI contest, the topic of the year is "Challenging Pandemics" with a direct or indirect link to COVID-19. We present Rebirth-20, an immersive application focusing on two axes: breathing and prevention against the spread of the virus. Using an Oculus Quest 2, we have developed a virtual world, enriched with different exercises. A prevention part allows the user to get familiar with gestures for stopping virus spread, such as washing hands and put on a mask. The purpose of the exercises is to help people affected by COVID-19 and having breathing difficulties.
\end{abstract}

Index Terms: Human-centered computing-Human computer interaction (HCI) - Interaction paradigms - Virtual reality;

\section{INTRODUCTION}

Since the end of 2019, the whole world is facing an unprecedented health crisis, due to COVID-19. For some people affected by the virus, when the virus retracts, it leaves scars on the lungs and creates damages, such as affecting the patient's ability to breath.

In the frame of the IEEE VR 3DUI contest, we aimed to develop an immersive application, called Rebirth-20, to help patients limit respiratory discomfort and regain a more relaxed pace of life. To our knowledge, no similar application was proposed before.

In the recovery phase, after the period of contagiousness, classical individual respiratory rehabilitation can be offered as well as exercise re-training, with prior medical evaluation.

We have been inspired by exercises recommended by aid associations for patients. The exercises aim to develop the physical fitness and well-being of the patients.

Rebirth-20 offers different types of exercises, including physical, breathing and relaxation. Through a soothing virtual world, accompanied by an avatar, the user is led to perform the various activities. Thanks to gestures and a breathing sensor, the avatar or the virtual world evolves along with the user through the exercises.

Finally, we want to highlight, through an interactive tutorial, the importance of keeping barrier gestures to fight against the spread of COVID-19.

\section{Theoretical Background and Rationale}

We decided to exploit two axes for the development of our application: breathing and prevention against the COVID-19.

We know now that the COVID-19 attacks the lungs. The lung is the most frequently affected organ in the disease, and epidemics caused by other coronaviruses such as Sars-CoV and Mers-CoV have shown that pulmonary fibrosis may persist after the initial infection. Interstitial pulmonary fibrosis is a frequent consequence of the respiratory distress seen in the acute phase of the disease. It

\footnotetext{
*e-mail: eloise_jeanne_claude.minder@ensam.eu

†e-mail: mael.sombret@ensam.eu

¥e-mail: jean-remy.chardonnet@ensam.eu

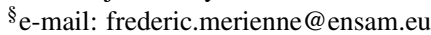

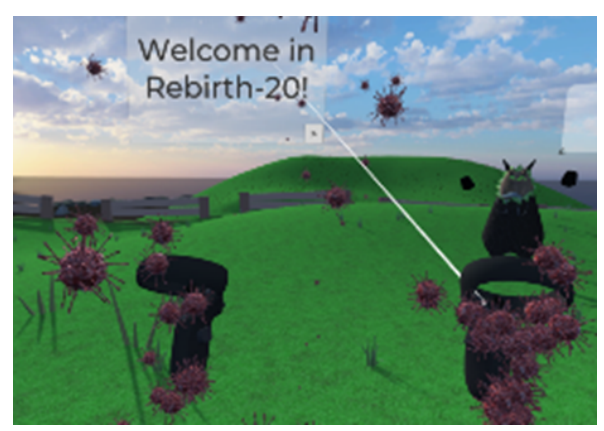

Figure 1: The Rebirth-20 application.

can also result from an acute phase of the disease that seemed to be benign [2].

To help patients with respiratory discomfort such as pulmonary fibrosis, simple exercises can be done. Several websites are available to assist patients with pulmonary fibrosis [5,7]. Exercises program can be found to develop the fitness and well-being of patients. We have been inspired by an exercise program developed by a French committee of physiotherapists, pulmonologists, psychiatrists and validated by a scientific council [1]. It is possible for us to translate some of the exercises in a virtual environment. Three types of exercises are offered:

- Relearn to breath: postures and breathing techniques

- Move: physical exercises

- Relax: technique to relax

The breathing axis of our application will therefore consist of a series of exercises aiming to help a patient with respiratory discomfort caused by COVID- 19 .

In addition, the virtual reality environment reduces the sensation of pain [3], which will help patients return to normal life. Indeed, psychological sequelae are to be feared in patients [2]. Therefore, we developed a soothing virtual world that is pleasing to the eye, like an oxygen bubble allowing the patients to temporarily escape their condition and the anxiety generated by the pandemic.

The second axis developed in the application is prevention and the importance of gestures making it possible to limit the transmission of the virus [8]. For example:

- Regularly wash hands

- Wear a mask

- Do not shake hands and avoid hugs

- Keep a distance of at least one meter from others

The goal of prevention is to interactively show the effects of the so-called barrier gestures. Thanks to virtual reality, prevention will gain a playful aspect and users should better integrate gestures.

\section{REBiRTH-20 Functionalities AND INTERACTIONS}

We have created a virtual world (Fig. 1), created in Unity3D and displayed in an Oculus Quest 2 HMD, pleasing to the eye and made of different scenes:

- A prevention scene with two different interactions

- One exercise in each of the categories mentioned above

- A free mode 
Table 1: Summary of the interactions between the real and virtual worlds, with the technology used.

\begin{tabular}{|c|c|c|}
\hline Real world & $\begin{array}{c}\text { Virtual world } \\
\text { interaction } \\
\end{array}$ & Technology used \\
\hline $\begin{array}{l}\text { Speech / cough } \\
\text { (prevention part) }\end{array}$ & $\begin{array}{c}\text { Particle cloud (wilts the } \\
\text { flowers and drops the } \\
\text { avatar) }\end{array}$ & VR headset microphone \\
\hline $\begin{array}{l}\text { Hand movements } \\
\text { (prevention part) }\end{array}$ & $\begin{array}{c}\text { Viruses on the } \\
\text { controllers - running } \\
\text { under water removes } \\
\text { them }\end{array}$ & Controller detection \\
\hline $\begin{array}{c}\text { Hand movements } \\
\text { (exercise \#1) }\end{array}$ & Grow a tree & Controller detection \\
\hline Breath (exercise \#2) & $\begin{array}{c}\text { Creation of a bubble }+ \\
\text { progress bar }\end{array}$ & VR headset microphone \\
\hline (exercise \#3) & Progress bar & $\begin{array}{l}\text { "A" button on the right } \\
\text { controller }\end{array}$ \\
\hline $\begin{array}{l}\text { Movement to "look at } \\
\text { your watch" }\end{array}$ & Navigation menu & $\begin{array}{l}\text { Menu button on the left } \\
\text { controller }\end{array}$ \\
\hline
\end{tabular}
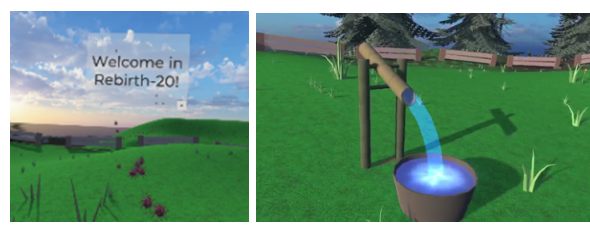

Figure 2: Preventing virus spread: a water fountain allows users to wash their hands to destroy the viruses stuck on the controllers.

\subsection{Interactions developed in the application}

Where practice permits, we have emphasized interactions in the virtual world. The implemented interactions are displayed in $\mathrm{Ta}-$ ble 1.

\subsection{Prevention scene}

In this scene, an avatar is present to guide the user through text bubbles. The avatar enumerates the rules, and the user can perform the different interactions: hand washing and put on a mask.

When the user talks or coughs, a virus cloud appears (Fig. 2) and drops the avatar. This cloud has also the power to wilt the flowers. We use the headset's embedded microphone to detect the sounds coming from the user. From the signal captured by the microphone, a sample of 128 values is stored in an array. The maximum value is retrieved, then compared to a threshold set in the script. After empirical tests, a value was set to detect whether the user is talking or coughing. 3D virus prefab objects are then instantiated correspondingly, with a starting point set to the position of the user's camera. Properties, such as "forces", are added randomly to give dynamics to viruses.

When the user puts on the virtual mask, the virus is no longer spread. The 3D object of the mask has a collision property which allows, when the user reaches the collision zone, to disable the virus generation script, described in the previous paragraph.

\section{Discussion}

Following an analysis of our application, we identified a list of improvements splitting into two parts: short term improvements that would allow a fully functional application, and then long term improvements.

Short term:

- Set up and use inertial sensors for the detection of breathing movements instead of using the microphone

- Add a short range teleportation for movement

- Add a human-like shadow
- Add a switch detection between hands and controllers

Long term:

- Add new exercises with different interactions

- Offer different worlds and accompanying avatars

- Improve the user experience: customize the canvas

- Perform experiments on a user group

- Obtain the opinion of health professionals

\section{CONCLUSION}

We created an immersive application to help people affected by COVID-19 and with respiratory disorders. We integrated an interactive prevention part, in the virtual world.

We created an island and forest type virtual world with ambient sounds. Five different scenes were developed to offer three exercises (breathing, warming up and relaxation), a prevention part and a free mode. To create exercises, we were inspired by a program written by healthcare professionals for patients with pulmonary fibrosis. For prevention, we were inspired by the gestures recommended to limit the spread of the Sars-CoV2 coronavirus. Interestingly, we have not identified any competing application. Applications similar to our project are focused either on breathing [6] or for physical training [4], but not both.

When starting the application, the first stage is prevention. Users follows the accompanying avatar's instructions, and performs interactions. For example, they will have to wash their hands to avoid catching any virus. They will also have the option to put on a mask, which will prevent the virus from spreading. Then users can use the menu to navigate through the exercises or the free mode.

In each exercise, different interactions with the world are proposed, depending on the actions performed. In the first one, a tree will grow, in exercise 2, bubbles will appear and in exercise 3 , a progress bar will have to be filled.

The free mode allows to walk freely in an area delimited by fences. The application is functional, but improvements can be made, such as the use of an inertial sensor on the user's torso to detect inhalation and exhalation movements. User experience can be improved by adding teleportation.

Long-term perspectives are also possible. For example, adding other exercises with different interactions, we could imagine having the application tested by a user group matching our target and improving the application through feedback. Finally, we could discuss with health professionals to further improve the application, and maybe have it validated by a health panel. This application could be marketed to the general public, or used in hospitals.

\section{REFERENCES}

[1] Ensemble contre FPI. Practical exercise program for patients with idiopathic pulmonary fibrosis. http://www.ensemblecontrefpi.com/.

[2] French National academy of medicine. Medical sequelae of covid-19: position statement of the national academy of medicine. http://www.academie-medecine.fr, July 2020.

[3] A. Gupta, K. Scott, and M. Dukewich. Innovative technology using virtual reality in the treatment of pain: Does it reduce pain via distraction, or is there more to it? Pain Medicine, 19(1):151-159, aug 2017. doi: 10. 1093/pm/pnx109

[4] INRIA. Verare : virtual reality at the service of the rehabilitation of patients with covid-19. https://www.inria.fr/en/verare-virtual-realityservice-rehabilitation-patients-covid-19, June 2020.

[5] Pulmonary fibrosis foundation. http://www.pulmonaryfibrosis.org/.

[6] C. Rockstroh, J. Blum, and A. S. Göritz. A mobile VR-based respiratory biofeedback game to foster diaphragmatic breathing. Virtual Reality, oct 2020. doi: 10.1007/s10055-020-00471-5

[7] B. Vainshelboim. Exercise training in idiopathic pulmonary fibrosis: is it of benefit? Breathe, 12(2):130-138, jun 2016. doi: 10.1183/20734735 .006916

[8] World Health Organization. How to protect yourself from covid-19. http://www.who.int/. 